\title{
Effect of fibreoptic bronchoscopy on pulmonary function
}

\author{
Andrew J Peacock, Ronald Benson-Mitchell, Richard Godfrey
}

\begin{abstract}
Several studies have shown that after fibreoptic bronchoscopy there may be a deterioration in lung function but it is not known whether this is due to the premedication, the topical anaesthetic, or the obstruction produced by the bronchoscope. The effects of each part of the procedure on spirometric measurements were studied in patients with lung disease and in normal nonsmokers. Measurements were made after premedication (papaveretum and atropine) in seven patients and after topical anaesthesia of the bronchial tree (340 mg lignocaine) with and without the bronchoscope in the trachea in 21 patients and 10 control subjects. Premedication had no effect. In the normal subjects lignocaine produced significant falls in $F E V_{1}$, forced vital capacity (FVC), peak expiratory flow (PEF), and peak inspiratory flow (PIF), and insertion of the bronchoscope caused further falls that were also significant. In the patients, however, although anaesthesia produced significant falls in $F E V_{1}$, FVC, PEF, and PIF of similar magnitude to those found in the normal subjects, there was no further important decrease when the bronchoscope was inserted. It is concluded that the major effect of bronchoscopy on lung function is due to topical lignocaine in the airways, and in patients with lung disease (excluding asthma or a central obstructing carcinoma) the insertion of the bronchoscope causes little additional obstruction.
\end{abstract}

It is well known that respiratory function may be disturbed after fibreoptic bronchoscopy, particularly in patients with lung disease. ${ }^{12}$ For example, when Salisbury et $a l^{2}$ studied lung function in normal subjects and patients with chronic airflow obstruction before and after fibreoptic bronchoscopy he found that airway resistance had increased by $23 \% \quad 15$ minutes after the procedure in the patients, but not in the controls. As no one has studied the changes in lung function during bronchoscopy we do not know whether the changes that occur are due to the premedication, the topical anaesthetic, or the physical presence of the bronchoscope in the airway. Nor do we know whether changes would have been found in the normal subjects in the study of Salisbury et al if measurements had been made with the bronchoscope in the airway. In an attempt to answer these questions we have performed spirometry in 21 patients with pulmonary disease and 10 normal control subjects before, during, and after bronchoscopy.

\section{Methods}

We studied 21 patients, 17 of them male, with pulmonary disease (16 with chronic airflow obstruction, mean $\mathrm{FEV}_{1}=2.18 \mathrm{l}$, and the remainder with fibrosing lung disease, mean $\mathrm{FEV}_{1} 2 \cdot 251$ ). They had a mean age of 59 (range 36-75) years. In all patients fibreoptic bronchoscopy was indicated as part of their clinical care. The ususal indication for bronchoscopy in the patients with airflow obstruction was suspicion of carcinoma, but none of the patients was shown to have an obstructing bronchial carcinoma. The patients with fibrosing alveolitis had bronchoscopy so that transbronchial biopsy specimens could be obtained. None of the patients was critically ill, or had a history of recent exacerbation of their lung disease. Patients with a history of asthma were excluded from the study because of the possible hazards of bronchoscopy in this group. We also studied 10 control subjects (six of them male), who were normal volunteers. All were non-smokers with normal pulmonary function and no history of atopy or respiratory disease (mean age 22 (21-23) years; mean FEV 13.9 l)

Each patient was studied in the following way. After premedication with intramuscular papaveretum $10 \mathrm{mg}$ and atropine $0.6 \mathrm{mg}$ they were placed in a comfortable semireclining position, which was the same for all subjects and kept constant during each study. A nose clip was used to prevent nasal airflow during spirometry, which was performed with a Morgan rolling seal spirometer connected to a Hewlett Packard 85B computer. This system generated inspiratory and expiratory flowvolume $(\mathrm{F}-\mathrm{V})$ loops, from which values for $F V_{1}$, forced vital capacity (FVC), peak expiratory flow rate (PEF), and peak inspiratory flow (PIF) were obtained. At least three F-V loops were obtained at each stage and the values associated with the best $\mathrm{FEV}_{1}$ were recorded. Continuous earlobe oximetry (Hewlett-Packard) was started to measure change in arterial saturation $\left(\mathrm{SaO}_{2}\right)$ before the instilliation of ligocaine. Two bronchoscopes were used: the Olympus BF type 1 T $10(6 \mathrm{~mm}$ tip) in 12 patients and the Olympus BF type 4B2 (4.9 mm tip) in 9 patients. The 10 control subjects were studied by the same method except that no premedication was given. Half the control subjects had bronchoscopy with the large bronchoscope and half with the
Address for reprint requests Dr A J Peacock, Medicine 1 , Centre Block, South Southampton SO9 $4 \mathrm{XY}$.

Accepted 2 October 1989 
smaller instrument. A pilot study on seven patients (five of them male; mean age 52, range 36-60 years) was carried out to assess the effect of premedication (papaveretum $10 \mathrm{mg}$ and atropine $0.6 \mathrm{mg}$, both given intramuscularly) on pulmonary function. The results indicated that no significant change in pulmonary function occurred after premedication, so the baseline results reported are those obtained after premedication.

Baseline values of maximal inspiratory and expiratory flow measurements were obtained before administration of the local anaesthetic. This was administered in the form of lignocaine $2 \%$ solution given in two ways (identical for all subjects): firstly, by spray to the nasopharynx (three $10 \mathrm{mg}$ puffs in each nostril, two to the back of the mouth, and two to inhale) and, secondly, in the form of $2 \mathrm{ml}$ aliquots administered through the bronchoscope. Two such doses were given to the vocal cords, one to the trachea, one to the main carina, and one to each of the left and right bronchi. A total of $340 \mathrm{mg}$ of lignocaine was given to each subject, after which the bronchoscope was removed. Spirometry was performed five minutes after the local anaesthetic. The bronchoscope was then reinserted transnasally and advanced to a point $5 \mathrm{~cm}$ above the main carina. Spirometry was repeated with the bronchoscope in position. Twenty minutes after the bronchoscopy spirometry was carried out for the final time.

To distinguish between the effects of local anaesthesia on the nasopharynx and the tracheobronchial tree, a further study was carried out to look at the effect of lignocaine spray given to the nasopharynx alone. Ten control subjects were asked to perform maximal inspiratory and expiratory flow-

Figure 1 Mean forced expiratory volume in one second $\left(F E V_{1}\right)$ and forced vital capacity (FVC) expressed as percentages of baseline values (standard errors indicated by bars) in patients $(\because)$ and control subjects (-): at baseline, five minutes after instillation of local anaesthetic but with bronchoscope removed ("Lignocaine"), with the bronchoscope in the trachea

("Bronchoscope"), and 20 minutes after bronchoscopy ("Recovery"). * $p<0.05$ in the comparison with baseline values.
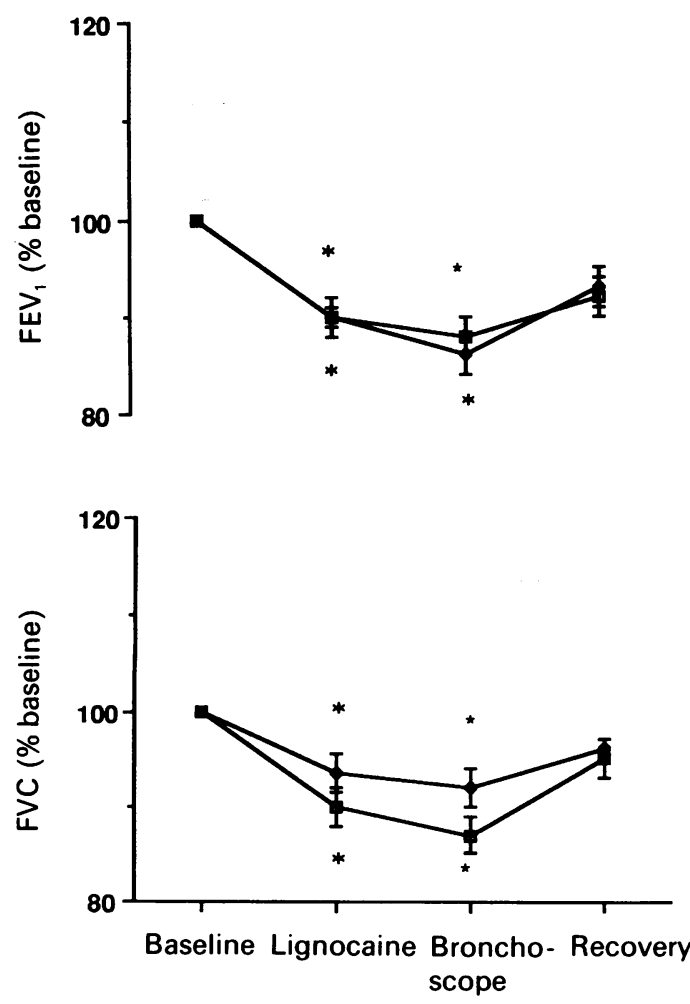
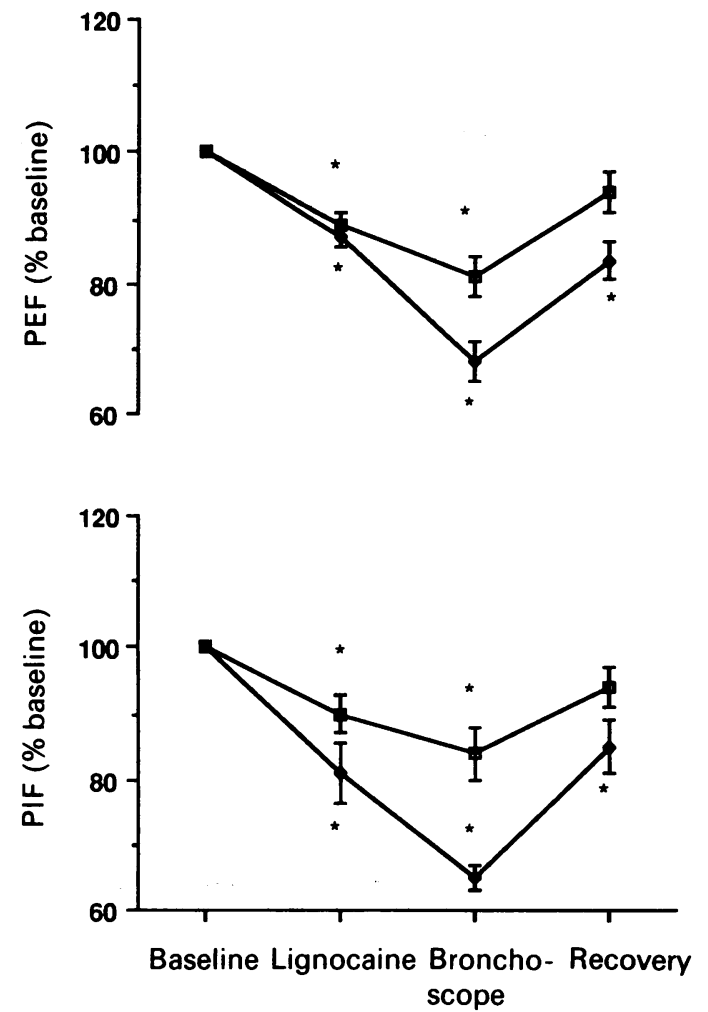

Figure 2 Mean peak expiratory flow (PEF) and peak inspiratory flow (PIF) expressed as percentages of baseline values (standard errors indicated by bars) in patients $(\because)$ and control subjects $(\neg)$ : at baseline, five minutes after instillation of local anaesthetic but with bronchoscope removed ("Lignocaine"), with the bronchoscope in the trachea ("Bronchoscope"), 20 minutes after bronchoscopy ("Recovery"). * $p<0.05$ ) in the comparison with baseline values.

volume manoeuvres before and after administration of lignocaine spray. This was given in the way described above-that is, a total of $100 \mathrm{mg}$ for each subject.

Because of the wide range of baseline pulmonary function in both the patients and the control subjects (baseline PEF in the patients varied from 120 to $620 \mathrm{l} / \mathrm{m}$ ), the results are expressed as percentages of baseline values. The significance of measured changes were assessed by means of paired Student's $t$ tests and results were considered significant if $\mathrm{p}$ was less then 0.05 .

All subjects gave informed consent to the study, which was approved by the human subjects committee of Southampton General Hospital.

\section{Results}

Topical lignocaine applied to the nasopharynx alone in the 10 control subjects caused no change in any measure of pulmonary function (mean $\mathrm{FEV}_{1} 3.91$ before anaesthesia and 3.81 afterwards). When applied to the major airways lignocaine produced a significant fall in $\mathrm{FEV}_{1}, \mathrm{FVC}, \mathrm{PEF}$, and PIF in both patients and normal control subjects (figs 1 and 2 and table). In patients the percentage changes in $\mathrm{FEV}_{1}, \mathrm{FVC}$ and inspiratory and expiratory flows were similar $(8.4-10.9 \%)$; in the control subjects the effect on FVC was smaller (table).

The insertion of the bronchoscope caused an additional fall in the same variables but this was significant only in the normal subjects, where the principal effect was on PEF and 
Spirometric variables and change from baseline in normal control subjects and patients during brochoscopy*

\begin{tabular}{|c|c|c|c|c|}
\hline & $F E V_{1}$ & $F V C$ & PEF & $P I F$ \\
\hline $\begin{array}{l}\text { NORMAL SUBJECTs } \\
\text { Mean (SD) absolute values at } \\
\text { baseline ( } 1 \text { or } 1 / \text { min) } \\
\text { Mean }{ }^{\circ} \text { (SEM) fall from baseline }\end{array}$ & $3.9(0.5)$ & $4.8(0.53)$ & $575.0(90 \cdot 0)$ & $495.0(85.0)$ \\
\hline $\begin{array}{l}\text { After lignocaine } \\
\text { Bronchoscope in airway } \\
20 \text { min after }\end{array}$ & $\begin{array}{r}10 \cdot 2(1.2) \\
13.8(3.0) \\
7.5(1.9)\end{array}$ & $\begin{array}{l}6.5(1.9) \\
8.0(2.0) \\
4.0(1 \cdot 1)\end{array}$ & $\begin{array}{ll}13.5 & (1 \cdot 5) \\
33.1 & (8 \cdot 0) \\
16.5 & (3 \cdot 1)\end{array}$ & $\begin{array}{ll}19 \cdot 3 & (4 \cdot 6) \\
32 \cdot 9 & (6 \cdot 0) \\
13 \cdot 6 & (3 \cdot 3)\end{array}$ \\
\hline $\begin{array}{l}\text { PATIENTS } \\
\text { Mean (SD) absolute values at } \\
\text { baseline ( ( o } 1 / \text { min) } \\
\text { Mean }{ }^{\circ} \text { (SEM) fall from baseline }\end{array}$ & $2 \cdot 2(0 \cdot 7)$ & $3.1(0.83)$ & $250.0(80.0)$ & $260.0(90.0)$ \\
\hline $\begin{array}{l}\text { After lignocaine } \\
\text { Bronchoscope in airway } \\
20 \text { min after }\end{array}$ & $\begin{array}{r}10 \cdot 8(2 \cdot 0) \\
12 \cdot 5(2 \cdot 0) \\
6 \cdot 0(2 \cdot 9)\end{array}$ & $\begin{array}{r}9 \cdot 1(2 \cdot 3) \\
12.7(1.5) \\
2 \cdot 0(2.0)\end{array}$ & $\begin{array}{rr}10.9 & (2.0) \\
19.3 & (6.0) \\
5.0 & (2.5)\end{array}$ & $\begin{array}{rr}8.4 & (2.8) \\
10.0 & (6.0) \\
2.0 & (3.0)\end{array}$ \\
\hline
\end{tabular}

*The changes due to lignocaine were significant in both patients and controls $(p<0.01)$ but the further reductions in these variables due to the insertion of the bronchoscope were significant $(p<0.05)$ only in the controls.

$\mathrm{FEV}_{1}$ - -forced expiratory volume in one second; FVC-forced vital capacity; PEF-peak expiratory flow; PIF-peak inspiratory
flow.

Figure 3 Successive maximal expiratory and inspiratory flow-volume loops for one typical normal subject: $(A)$ at baseline; (B) five minutes after instillation of local anaesthetic but with bronchoscope removed; (C) with the bronchoscope in the trachea. The shapes of the flow-volume loops were consistent at all stages of the procedure for both the patients and the normal subjects.

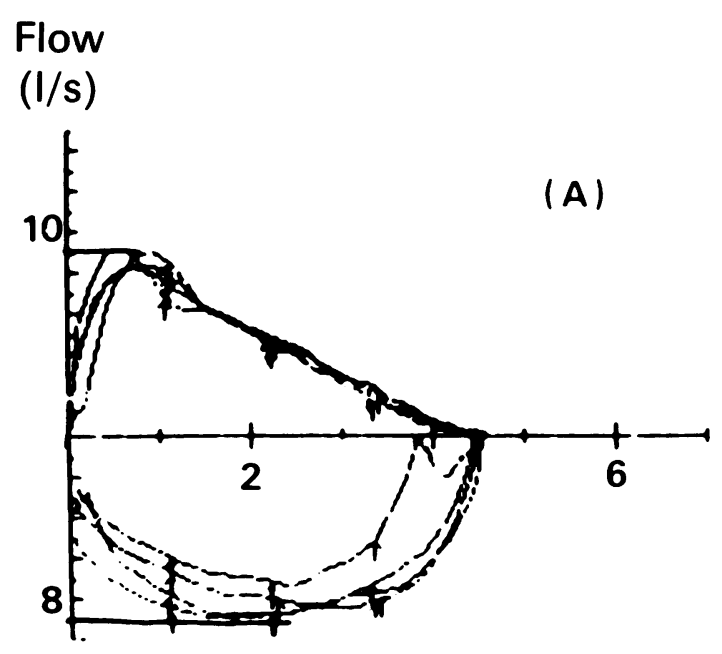

PIF (fig 2 and table). This is shown graphically in the flow-volume loops from a typical normal subject (fig 3 ).

After removal of the bronchoscope respiratory function improved in all patients, and by 20 minutes after removal only the $\mathrm{FEV}_{1}$ (still reduced by $8 \%$ ) had not returned to baseline values. In the control subjects, however, although the $\mathrm{FEV}_{1}$ and FVC were almost back to baseline, PEF and PIF were still clearly reduced (by $17 \%$ and $15 \%$ ). The pattern of change in patients with fibrosing lung disease was similar to that in the group as a whole (for example, the mean fall in $\mathrm{FEV}_{1}$ after application of lignocaine in the patients with fibrosing lung disease was $18 \%$ and the fall in FVC $14 \%$, with no further change when the bronchoscope was inserted). There was no consistent relation between baseline lung function and the percentage fall in any

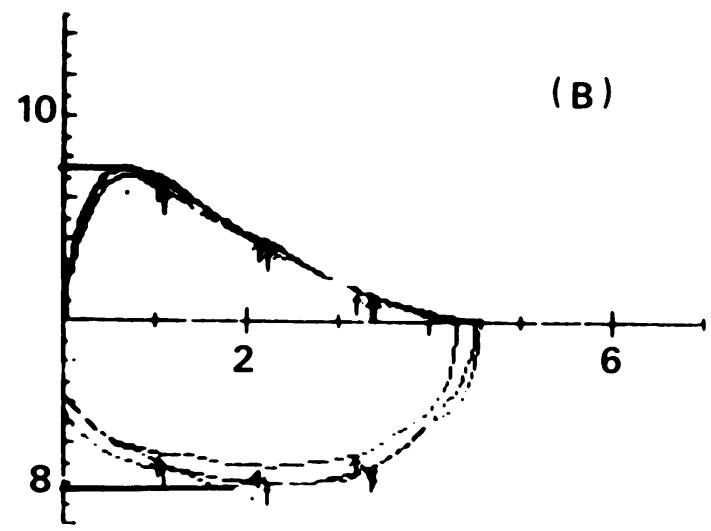
variable, though there was a tendency for there to be a greater fall in the variable when the baseline measurement was reduced (for example, the two patients with an $\mathrm{FEV}_{1}$ of around 1.01 had a mean percentage fall in $\mathrm{FEV}_{1}$ of $19 \%$ after lignocaine, whereas the two with values of about 3.01 had a mean fall of $9 \%$ ). There were no differences between the effects of the small and large bronchoscopes in either the patients or the control subjects.

There was no significant change in arterial oxygen saturation in either patients or control subjects at any stage of the procedure. The mean (SEM) fall in $\mathrm{SaO}_{2}$ in the patients was $0.2 \%(0.25 \%)$ after instillation of lignocaine and $0.9 \%(0.4 \%)$ after insertion of the bronchoscope.

\section{Discussion}

In this study fibreoptic bronchoscopy caused a significant fall in forced expired volumes and inspiratory and expiratory airflow in both patients and normal subjects. These changes have been reported previously but we were able to show that they occurred mainly after administration of the lignocaine local anaesthetic. Subsequent insertion of the bronchoscope caused some additional fall in airflow but in the patients this was relatively small by comparison with the effect of the local anaesthetic. 
Further evidence of the relatively minor contribution to airflow obstruction caused by the bronchoscope was provided by the finding that the changes in spirometric values were the same whether the large or the small instrument was used. Lindholm et $a l^{\beta}$ calculated that a bronchoscope should reduce the cross sectional area of the trachea by 10 $15 \%$, causing a twofold rise in airway resistance. In our study insertion of the bronchoscope reduced PEF and PIF (though not $\mathrm{FEV}_{1}$ and FVC) significantly in the normal subjects but not in the patients. The explanation for this is probably that the major site of airway resistance in normal people lies in the main bronchi whereas in patients with chronic airflow obstruction it lies distal to the trachea and the major bronchi, so that the effect of the bronchoscope lying in the trachea was not detected. An important point, however, is that none of our patients had obstructing carcinomas. If such carcinomas had been present the effect of the bronchoscope on airflow might have been greater.

The flow-volume loops were very reproducible in both patients and control subjects (fig 3). The changes we found therefore seem unlikely to be due to measurement error. Peak flow rate varies with lung volume, so some of the change in these variables might have been due to a change in total lung capacity (which we did not measure). The changes in flow, however, were most dramatic in the normal subjects, who had minor changes in FVC, and change in both total lung capacity and residual volume is unlikely without change in vital capacity.

The premedication given to the patients had no effect on respired lung volumes or flow. Indeed, the atropine may have been partially protective because the insertion of the bronchoscope had a greater effect on the controls (who did not have premedication) than on the patients (who did).

Earlobe measurement of arterial oxygen saturation showed no important change after administration of lignocaine or insertion of the bronchoscope in either patients or control subjects. This does not exclude small changes in arterial oxygenation during the studies as all the patients were on the upper, flat sections of their oxygen dissociation curves. When arterial oxygen tension has been measured during fibreoptic bronchoscopy ${ }^{4-8}$ significant changes have been found, but we opted for measurement of $\mathrm{SaO}_{2}$ as a less invasive procedure in what was already a demanding protocol.

Our results suggest that the major cause of increased airflow obstruction during bronchoscopy was the topical lignocaine, but the reason for this effect is not clear. This is an important finding because the cause may be preventable. The administration of lignocaine via the bronchoscope, before anaesthesia of the airway, evidently produced irritation in most of our subjects because most coughed. Thus lignocaine may be a primary irritant but, if so, the mechanism is unknown.
The bitter taste of lignocaine may be a nonspecific noxious stimulus, but the fact that the application of lignocaine to the nasopharynx alone in the control subjects had no effect suggests that this was not the pathway in our subjects.

It is well known that lignocaine may induce bronchoconstriction in subjects with hyperreactive airways, ${ }^{910}$ and Weiss and Patwardhan ${ }^{9}$ suggested that this might be mediated by prostaglandin $F_{2 x}$. Newball et $a l,{ }^{11}$ however, showed that atropine pretreatment did not prevent the bronchoconstrictor response to prostaglandin $F_{2 x}$, in contrast to its effect on lignocaine induced bronchoconstriction. Fish and Peterman $^{10}$ showed that intramuscular or nebulised atropine almost totally abolished the bronchoconstrictor response to lignocaine in asthmatic subjects, suggesting that the effect of lignocaine might be mediated by the vagus nerve.

The bronchoconstrictor effects of lignocaine solution may be related to the physicochemical properties of the solution in which it is administered. The $\mathrm{pH}$ of $2 \%$ lignocaine is about 6.6 and that of the $4 \%$ solution even lower; a solution at room temperature $\left(20^{\circ} \mathrm{C}\right)$ is normally used and the solution available for injection directly down the bronchoscope is made up in distilled water. Several studies have shown that distilled water is a potent bronchoconstrictor, especially in patients with bronchial hyperreactivity. It would seem prudent to use a warmed solution made up in normal saline no more than $2 \%$ in strength. If the bronchoscopy were also preceded by administration of nebulised atropine (or, presumably, ipratropium, though this needs to be confirmed), the morbidity associated with the procedure should be reduced and patients previously thought to be unfit for bronchoscopy - paradoxically those who may need it most-could be examined with a greater margin of safety.

1 Matsushima Y, Jones RL, King EG, Moysa G, Alton JDM. Alterations in pulmonary mechanics and gas exchange during routine fibreoptic bronchoscopy. Chest 1984;

2 Salisbury BG, Metzger LLF, Altose MD, Stanley NN, Cherniak NS. Effect of fibreoptic bronchoscopy on respiratory performance in patients with chronic airways obstruction. Thorax 1975;30:441-6.

3 Lindholm CE, Ollman B, Snyder JV, Miller EG, Grenvik A. Cardiorespiratory effects of flexible fibreoptic bronchoscopy in critically ill patients. Chest $1978 ; 74: 362-8$.

4 Dubrawsky C, Awe RJ, Jenkins DG. The effect of bronchofibrescopic examination on oxygenation status. Chest 1975;67:137-40.

5 Randazzo GP, Wilson AF. Cardiopulmonary changes during flexible fibreoptic bronchoscopy. Respiration 1976 33:143-9.

6 Albertini RE, Harrell JH, Moser KM. Management of arterial hypoxemia induced by fibreoptic bronchoscopy. Chest 1975;67:134-6.

7 Karetzky MS, Garvey JW, Brandstetter RD. Effect of fibreoptic bronchoscopy on arterial oxygen tension. $N Y$ State J Med 1974;1:62-3.

8 Albertini RE, Harrell JH, Kurihar N, Moser KM. Arterial hypoxemia induced by fibreoptic bronchoscopy. JAMA 1974;230:1666-7.

9 Weiss EB, Patwardhan AV. The response to lidocaine in bronchial asthma. Chest 1977;72:429-38.

10 Fish JE, Peterman VI. Effects of inhaled lidocaine on airway function in asthmatic subjects. Respiration 1979;37:201-7.

11 Newball JJ, Keiser WR, Lenfant CJ. Influence of cromolyn plus atropine on prostaglandin $F_{2}$ alpha induced bronchoconstriction in asthmatics. Clin Res 1974;22:510. 